\title{
The Only Way to Eradicate COVID-19 Pandemic from the World
}

\author{
Iraj Salehi-Abari \\ Rheumatology Research Center (RRC), Faculty of Medicine, Tehran University of Medical Sciences (TUMS), Tehran, Iran \\ Email: salehiabari@sina.tums.ac.ir
}

How to cite this paper: Salehi-Abari, I. (2020) The Only Way to Eradicate COVID19 Pandemic from the World. Advances in Infectious Diseases, 10, 129-135. https://doi.org/10.4236/aid.2020.103013

Received: July 10, 2020

Accepted: August 9, 2020

Published: August 12, 2020

Copyright $\odot 2020$ by author(s) and Scientific Research Publishing Inc. This work is licensed under the Creative Commons Attribution International License (CC BY 4.0).

http://creativecommons.org/licenses/by/4.0/ (c) (i) Open Access

\begin{abstract}
The novel Coronavirus disease or COVID-19 is a new contagious, dangerous, and deadly viral/immunological systemic disorder with predominantly respiratory features caused by human infection with SARS-CoV-2, which is rapidly spreading from person-to-person all around the world as a pandemic. If the COVID-19 pandemic is not controlled, and then eradicated, it will probably cause the extinction of the human race in the coming years or decades! It shows the fastest multiple genetic mutation for SARS-CoV-2 in the development of the disease. According to the author of this article, an effective vaccine for SARS-CoV-2 will not be made any time soon or may never be made. If it is made, due to the need to use the vaccine several times a year, the staggering cost of vaccine production, its potentially insufficient effect in preventing COVID-19, its possible side effects, and the complexity of its equitable distribution worldwide, it cannot be a significant success in preventing the COVID-19 pandemic. Hence, the only way to eradicate COVID-19 pandemic is: simultaneous, synchronized, and universal quarantine for at least 40 days for all the people of the planet as staying at home for $99 \%$ of them and staying at workplace for another $1 \%$, that because of the need for their key job, they need to be present at work. By applying the COVID-19 Referral System for screening people infected with SARS-CoV-2 and Persian Gulf Criteria for diagnosis of COVID-19, we recommend home isolation for mild cases of COVID-19 and hospitalization in Corona Center for severe cases. Also, along with these, more and more SARS-CoV-2 diagnostic tests should be performed using highly sensitive kits, and the principles of prevention of becoming infected with the SARS-CoV-2 should be followed carefully and as soon as possible. By applying all the above, success in controlling and suppressing the SARS-CoV-2 epidemics is anticipated.
\end{abstract}

\section{Keywords}

COVID-19, SARS-CoV-2, Quarantine, Novel Coronavirus, Pandemic, Persian 
Gulf Criteria, Referral System

\section{Introduction}

The novel Coronavirus disease or COVID-19 is a new contagious, dangerous, and deadly viral/immunological systemic disorder with predominantly respiratory features caused by human infection with SARS-CoV-2, which is rapidly spreading from person-to-person all around the world as a pandemic. If the COVID-19 pandemic is not controlled, and then eradicated, it will probably cause the extinction of the human race in the coming years or decades! Because the SARS-CoV-2 is transmitted in many ways, rapidly and exponentially from person to person, from environment to person, or from person to environment. This virus is super-saturated for hours to days in many places/spaces, so that a moment's presence and breathing in such places/spaces is enough to get COVID19. Not only sneezing, coughing, shaking hands and kissing can cause COVID19, but also talking and breathing normally and even gas passing from the intestine can cause the disease [1] [2] [3]. Failure to adhere to ten rules preventing COVID-19 especially non-compliance with physical distancing and staying at home, failure to hand washing and non-use of face-mask will also contribute to the spread of the disease [4]. But the most dangerous part of the story is that the COVID-19 pandemic is like an iceberg, $80 \%$ of which is invisible, and we only see $20 \%$ of the mountain. In other words, $80 \%$ of patient, carriers and spreaders of SARS-CoV-2 are asymptomatic/invisible, and only $20 \%$ of them are identifiable. Indeed, we have a huge group of silent spreaders of SARS-CoV-2 include: Carrier state for SARS-CoV-2, Subclinical COVID-19, Pre-symptomatic COVID19 within the incubation period and Mild COVID-19. We have to know that following a contact; the transmission probability of virus: 1) From a SARSCoV-2 carrier without a mask, to a healthy person with a mask is 70\%,2) From a SARS-CoV-2 carrier with a mask, to a healthy person without a mask is $5 \%, 3$ ) From a SARS-CoV-2 carrier with a mask, to a healthy person with a mask is $1.5 \%$ and finally 4) From a SARS-CoV-2 carrier without a mask, to a healthy person without a mask is $\geq 90 \%$. The above cases are silent spreaders, who have a major role in the spread of SARS-CoV-2 [4]. In other words, they can spread SARS-CoV-2 for up to 2 weeks. If such a person passes by an average of 100 people daily without physical distancing, and both face-masks are not worn; there is a $90 \%$ chance, and if only the silent spreader is without a face-mask; there is a $70 \%$ chance that the other person will get it. This means that 90 and 70 people will be infected with the SARS-CoV-2 on a daily basis, respectively, of which, $40 \%$ will be asymptomatic, $40 \%$ will suffer from mild COVID-19, and $20 \%$ of cases will be severe/critical and cause hospitalization, and in the end, $5 \%$ of all these people will die. Then, if we multiply the resulting numbers by 14 , the results are two rows of numbers, which in order from left to right, indicate: the 
new cases of COVID-19 in the forms of: asymptomatic, mild, hospitalized candidates, and dead cases within 14 days:

$\begin{array}{llll}504, & 504, & 252, & 63 \\ 392, & 392, & 196, & 49\end{array}$

This is due to the presence of an asymptomatic person infected with SARS$\mathrm{CoV}-2$ that has the personalities of ignorant, thoughtless, selfish, incomprehensible, unconscious, or a complex person that is called "More Dangerous than a Zombie" who refuses to the face-mask is not applied. Of course, provided that the government financially supports the poor and needy in society. Asymptomatic and mild COVID-19 patients, who make up 80\% of cases, recover after 2 to 3 weeks. Moderate to severe COVID-19 patients usually recover within 3 to 6 weeks but the recovery in critical cases of COVID-19 varies with the person [4] [5] [6] [7] [8]. We have to know that; at least six major subtypes of SARS-CoV-2 have been detected in less than six months since the onset of novel Coronavirus pandemic. This shows the fastest genetic mutation for a virus in the development of the disease, also the emergence of acquired natural immunity following COVID-19 may be questionable, because multiple reports of COVID-19 recurrence in patients, and multiple cases of lack of adequate antibody response to the virus have been observing [4] [5] [6] [7] [8]. Although the original image of COVID-19, which was introduced to the world from China, showed it to be much calmer than influenza, with far fewer death?! But by looking at the SARSCoV-2 epidemics in Europe and the United States, we find that we are facing a very deadly and pervasive disease, ten times more than influenza [4] [5] [6] [7] [8]. According to the author of this article, an effective vaccine for SARS-CoV-2 will not be made any time soon or may never be made, and even if it is made, due to the need to use the vaccine several times a year, the staggering cost of vaccine production, its potentially insufficient effect in preventing COVID-19, its possible side effects, and the complexity of its equitable distribution worldwide, it cannot be a significant success in preventing the COVID-19 pandemic. As a principle in medicine prevention precedes treatment, especially for vir$\mathrm{al} /$ contagious disorders that lead to epidemics/pandemic. The rule is to control and limit the transmission of the virus and ultimately the eradication of it. If we were to allow the virus to continue to live, grow, multiply and transmit in human life, and we would produce billions of vaccines a year and vaccinate all the people of the planet several times to influence them to be resistant against virus and less susceptible to it, then if some people get a viral disease despite receiving a vaccine or refusing to be vaccinated, let us keep ourselves busy making and producing medicine for the disease. In fact, we have surrendered to the will of the virus. In which case human destiny and life are influenced by the most lethal and contagious virus in the world. In fact, the military parade of all humanity against the virus, if carried out with strength, order, unity and coordination, we will be able to defeat and destroy the virus. So, If the COVID-19 pandemic is not controlled, and then eradicated, it will probably cause the extinction of the human race in the coming years or decades. A way to serious control the disease 
and possibly eradicate it must be provided; our guess is that the only way to achieve global success in the face of novel Coronavirus pandemic is to unite all the states and nations of the world to establish a complete, simultaneous, synchronized, universal, and integrated quarantine for at least 40 days for all the people of earth globe as staying at home for $99 \%$ of them and staying at workplace for another $1 \%$, that because of the need for their key job, they need to be present at work. By applying the COVID-19 Referral System for screening people infected with SARS-CoV-2 and Persian Gulf Criteria for diagnosis of COVID-19, we recommend home isolation for mild cases of COVID-19 and hospitalization in Corona Center for severe cases [4]. Also, along with these, more and more SARS-CoV-2 diagnostic tests should be performed using highly sensitive kits, and the principles of prevention of becoming infected with the SARS-CoV-2 should be followed carefully and as soon as possible. If all of the above apply, success in controlling and suppressing the SARS-CoV-2 epidemics will not be unexpected. The governments and nations of Vietnam, Singapore, Taiwan (China), Finland, Germany, South Korea, Japan, Canada, and Cuba, that are thought to be among the most successful countries in controlling the novel Coronavirus epidemics should be a model for other governments and nations [4]. We have to admit that if the SARS-CoV2 is not completely controlled or eradicated, it will eat the tree of humanity like a termite until one day it suddenly collapses, pulverizes and disappears. Indeed, how long can we witness the emergence and continuation of a mysterious and highly contagious disease with a thousand faces and unpredictable and suddenly fatal conflicts called COVID-19. A disease that, even if it does not kill suddenly, gradually challenges the health and life of the person in such a way that every day one wishes that the disease took its life in the first days.

\section{Study Approach}

Governments can succeed against the SARS-CoV-2 epidemic when they prioritize the health of society and the lives of their citizens over economic, political, military, religious, and ideological issues. Providing accurate and real statistics regarding COVID-19, the number of patients and deaths, by the governments, and the existence of honesty and truthfulness in the thinking, expression, and performance of government officials. The government's empathy with the nation and national determination and unity, are necessary for success in controlling SARS-CoV-2 epidemic [4]. If a government falsely reports the statistics of COVID-19, it will not only fail to control the SARS-CoV-2 epidemic in the country but will also disrupt the control of the SARS-CoV-2 pandemic in the world [4]. In his book, Golestan, Saadi Shiraz has presented a very meaningful poem entitled Bani Adam, which is:

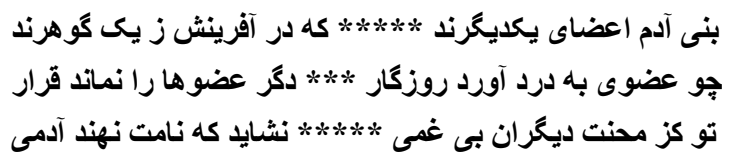


Human beings are members of a whole,

In creation of one essence and soul.

If one member is afflicted with pain,

Other members uneasy will remain.

If you've no sympathy for human pain,

The name of human you cannot retain

To achieve global quarantine, we need the support and coordination of the World Bank, the International Monetary Fund (IMF), the world Health Organization (WHO), the Food and Agriculture Organization (FAO), the Food and Drug Administration (FDA), the top 20 economic powers in the world, and eight industrialized countries of the world (G8), and especially China, USA, Russia, Germany, Britain, France, Japan, South Korea, Canada and Australia. Countries that are the center of agriculture, food, and medicine have a key role to play. It is suggested that China, as one of the world's top economic powers and one-fifth of the world population, is the source of novel Coronavirus pandemic in the world, and its government has a one-month delay in announcing novel Coronavirus epidemic of China; fund one-fifth of the World Bank and the International Monetary Fund. All countries can implement this 40-day quarantine according to an international timetable if all countries have adequate financial, food, pharmaceutical and health support and management. If this pandemic is not eradicated and its continuation does not exterminate the human race on the planet in the next ten years, it will remain with humanity for decades and even centuries, and returning to the world before 2020 will be a dream. Unfortunately, our planet is full of religious, ethnic, racial, skin color, language and culture differences, and many governments are colonizing and exploiting the people of their land. Instead of serving the health, vitality, comfort, tranquility and well-being of their citizens, many governments are plundering, and embezzling the wealth of their people by creating an atmosphere of repression and terror, and perhaps they see the continuation and spread of the novel Coronavirus epidemic in their own interests.

\section{Discussion}

The Persian scholar of medicine Avicenna (980-1037) suspected that some diseases were spread by microorganisms, and to prevent human to human contamination, he came up with the method of isolating people for 40 days in Persian is called Cheleh. Traders from Venice saw his success and took this knowledge back to Italy and called it quarantine (forty in Italian). This is the origin of the word quarantine to fight pandemics, another bright idea coming from ancient Persia (Iran). Also, the historical history of using face masks goes back to the civilization of ancient Iran. And at present, the Persian Gulf Diagnostic Criteria has been presented with extremely high sensitivity and accuracy to identify COVID-19 from the territory of Iran [4]. I, not as Dr. Iraj Salehi-Abari, but as an Iranian physician from the land of Cyrus the Great, the country to which human 
civilization owes, the cradle of the most glorious civilization in human history, the birthplace of human rights and the oldest origin of medical sciences, land of Alchemist (inventor of the theory of atom, ie Democritus) Artakhe (aware of structural engineering), Barbad (great musician), Bozorgmehr (symbol of wisdom and skill), Ferdosi, Hafez, and Saadi, Abu Rihan Biruni, Khajeh Nasir al-Din Tusi, Mohammad zakaria Razi and Ebne Sina, declare and war the global mafia hidden behind the scenes of politics, which dominates most of the world's regimes and the entire economy and wants to take advantage of the novel Coronavirus pandemic, should know that the mafia era is over and because of the novel coronavirus pandemic, the ship of the inhabitants of the earth globe has been punctured, which is a big hole. If this hole is not repaired, not only the population masses but also the mafia of power and wealth will drown with them. SARS-CoV-2 does not recognize mafia and non-mafia. They don't think they can produce an exclusive drug or vaccine for themselves and their families, to achieve an aristocratic life after the major death of the population of the planet and to divide the sovereignty and ownership of the lands among their children. The author of this article with a firm belief in God, the Creator of the Universe; the main judge and constant observer of our imagination, speech, and actions; the infinite source of humanity, sciences, wealth, and power; our only eternal love and true friend; the God against him/her the whole universe is of little value, swears that; if all people in the world do not face this pandemic in a united way, they will not to be able to survive or the years before 2020 will join the dreams and history. Those who lose God, even if they gain the whole universe, will be the greatest losers, and those who have God will be the richest and most powerful people on earth. Do you know when we lose God? Yes: 1) With the first dollar we stole from people's pockets. 2) With the first heart we break, even with the first tear that flows. 3) With the slightest harm to others, even as much as a drop of blood. And, do you know when we get God? Yes, of course: 1) By making a person's heart happy. 2) By holding the hands of an incapacitated person. 3) By eliminating a need in a person and finally; 4) As long as we are useful to the people and do not bite them. If we walk in the path of humanity and make good thoughts, good words, and good deeds our profession and resort to science, knowledge and research in life, we will join God in worldly happiness. Remember that the God has always been, is and will be the absolute owner and ruler of the universe, and that we can neither deceive yourself nor the God of the universe.

\section{Conclusion}

The SARS-CoV-2 has emerged to remind people that the only way for human survival, health and well-being is through the equitable distribution of wealth, amenities, shelter and food, and health care. It points out that the only way to properly manage communities is to avoid mismanagement; entrusting tasks to skilled and worthy people who are compassionate and kind. To overcome the 
SARS-CoV-2 pandemic, humanity must put aside ethnic, religious, racial, skin color, cultural and linguistic differences, because these issues are trivial. All nations and governments must live united as the human family and the inhabitants of the one common home, the planet, in the shadow of peace, friendship and tranquility. Governments, instead of war/killing and all these weapons factories/military equipment and nuclear arsenals, should be invested in food production, health and medicine, and the production of science and research. All people must step on the path of humanity as soon as possible and in an integrated way, and walk away from all that are prejudice, superstition and backwardness by using science and scientific solutions. In the SARS-CoV-2 pandemic, when the governments provide financial support to the poor and needy in a just manner; people who are closer to humanity and science will have a better chance of survival. In conclusion, it is enough for a global will to quarantine all the people of the planet simultaneously and seamlessly for 40 days in order to eradicate the SARS-CoV-2 pandemic from this planet.

\section{Conflicts of Interest}

The author declares no conflicts of interest regarding the publication of this paper.

\section{References}

[1] Gu, J.Y., Han, B. and Wang, J. (2020) COVID-19: Gastrointestinal Manifestations and Potential Fecal-Oral Transmission. Gastroenterology, 158, 1518-1519. https://doi.org/10.1053/j.gastro.2020.02.054

[2] Cicuttin, E., Cobianchi, L., Chiarugi, M., Catena, F., Coccolini, F. and Pietrabissa, A. (2020) Detect to Protect: Pneumoperitoneum Gas Samples for SARS CoV 2 and Biohazard Testing. Surgical Endoscopy, 34, 2863-2865. https://doi.org/10.1007/s00464-020-07611-7

[3] World Health Organization (2020) Transmission of SARS-CoV-2: Implications for Infection Prevention Precautions: Scientific Brief, 9 July 2020. No. WHO/2019nCoV/Sci_Brief/Transmission_modes/2020.3.

[4] Salehi-Abari, I., Khazaeli, S., Salehi-Abari, F. and Salehi-Abari, A. (2020) Practical Guideline for Screening the Patients with SARS-CoV-2 Infection and Persian Gulf Criteria for Diagnosis of COVID-19. Advances in Infectious Diseases, 10, 67-93. https://doi.org/10.4236/aid.2020.103008

[5] Information \& Resources. National Jewish Health Coronavirus. https://www.prnewswire.com/news-releases/national-jewish-health-offers-expande d-covid-19-antibody-testing-301073900.html

[6] CDC: Centers for Disease Control and Prevention CDC 24/7: Saving Lives, Protecting People; Coronavirus COVID-19.

https://www.cdc.gov/media/dpk/diseases-and-conditions/coronavirus/coronavirus2020.html

[7] News regarding COVID-19: American Academy of Otolaryngology-Head and Neck Surgery.

[8] WHO (2020) News and Events regarding COVID-19 and SARS CoV-2. https://www.who.int/news-room/commentaries/detail/transmission-of-sars-cov-2-i mplications-for-infection-prevention-precautions 